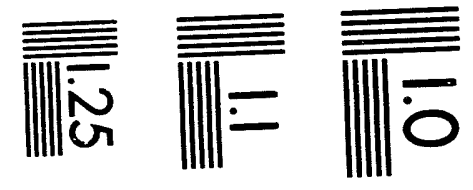

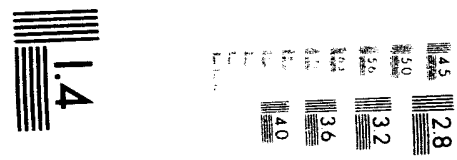

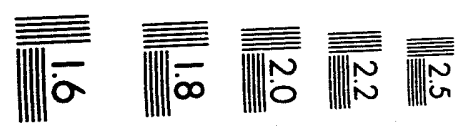



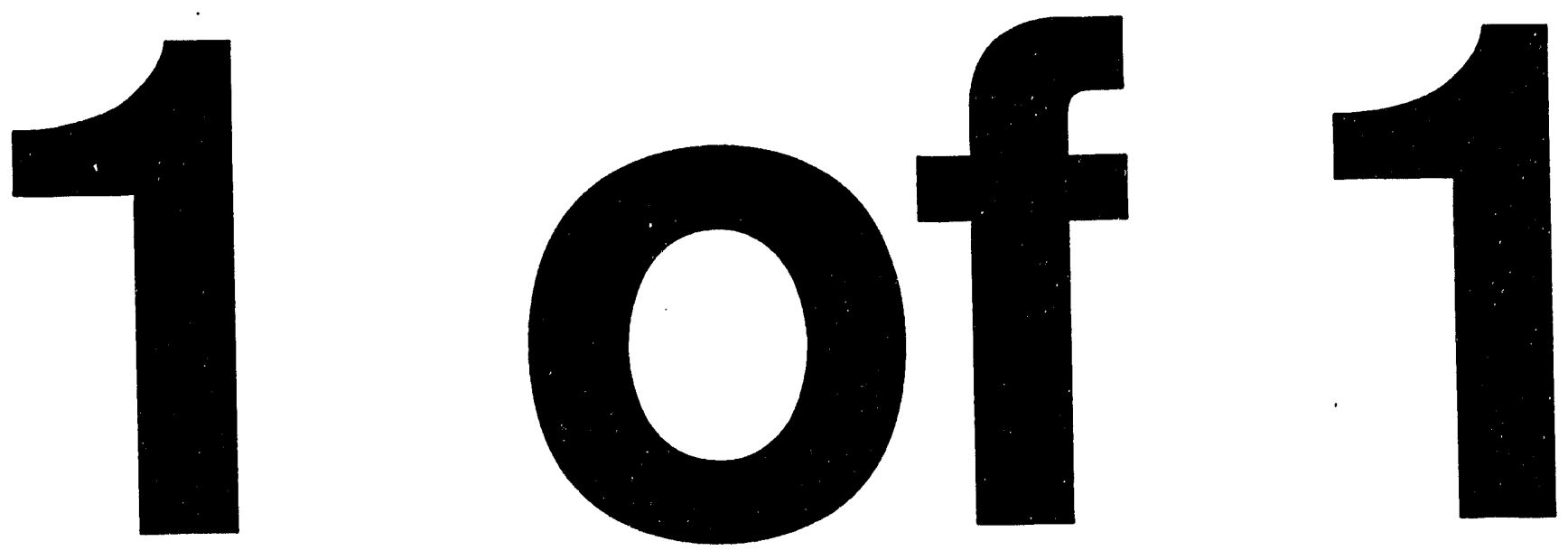


\section{PERIODS OF ENHANCED TRANSPORT DURING H-MODE IN PBX-M}

BY

S. SESNIC, J. DUNLAP, R. KAITA, ET AL.

FEBRUARY, 1994

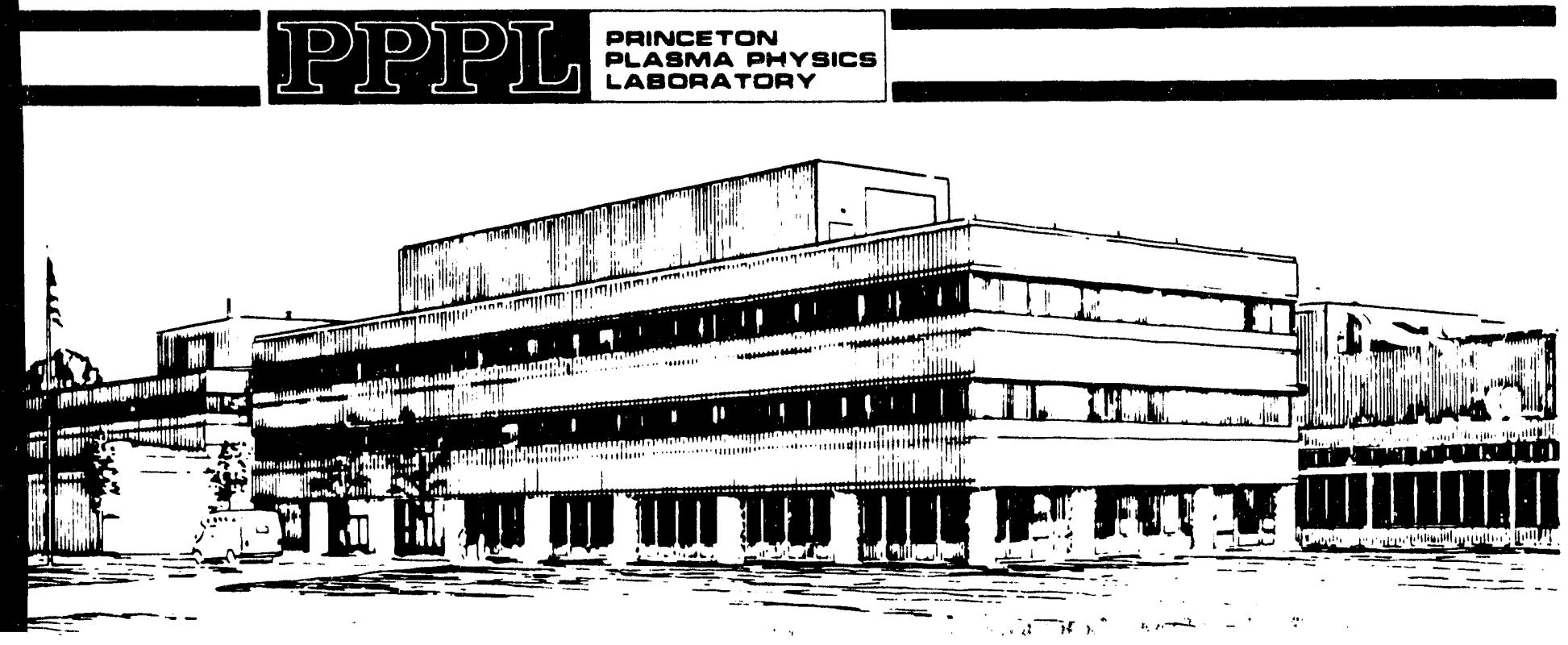




\section{NOTICE}

This report was prepared as an account of work sponsored by an agency of the United States Government. Neither the United States Government nor any agency thereof, nor any of their employees, makes any warranty, express or implied, or assumes any legal liability or responsibility for the accuracy, completeness, or usefulness of any information, apparatus, product, or process disclosed, or represents that its use would not infringe privately owned rights. Reference herein to any specific commercial produce, process, or service by trade name, trademark, manufacturer, or otherwise, does not necessarily constitute or imply its endorsement, recommendation, or favoring by the United States Government or any agency thereof. The views and opinions of authors expressed herein do not necessarily state or reflect those of the United States Government or any agency thereof.

\section{NOTICE}

This report has been reproduced from the best available copy.

Available in paper copy and microfiche.

Number of pages in this report: 16

DOE and DOE contractors can obtain copies of this report from:

Office of Scientific and Technical Information

P.O. Box 62

Oak Ridge, TN 37831;

(615) 576-8401.

This report is publicly available from the:

National Technical Information Service

Department of Commerce

5285 Port Royal Road

Springfield, Virginia 22161

(703) $487-4650$ 


\title{
Periods of Enhanced Transport During H-Mode in PBX-M
}

\author{
S. Sesnic, J. Dunlap*, R. Kaita, S. M. Kaye, and M. Okabayashi \\ Princeton Plasma Physics Laboratory, Princeton University, P.O. Box 451, \\ Princeton, New Jersey 08543, USA
}

\begin{abstract}
In PBX-M, periods of enhanced transport are often observed in high $\beta_{\text {pol }}$ H-mode discharges. They can reduce the energy confinement time by a factor of two. Their duration is typically between 2 to $20 \mathrm{~ms}$. They are followed by periods of normal transport of a similar duration. These periods of enhanced transport consist of a series of turbulent $m=e v e n$ MHD events, starting several $\mathrm{cm}$ inside the plasma edge. They propagate into the confinement region in $600 \mu \mathrm{s}$, causing a progressive erosion of the profile. Each $\mathrm{m}=$ even event can also cause an energy loss of $1 \%$ or less, mainly from the confinement region. These $m=e v e n$ events are reminiscent of grassy ELMs.
\end{abstract}

\section{Introduction}

Supplementary heating, either neutral beam or wave heating, has been shown to produce a deterioration in energy and particle confinement in present day tokamaks. Many studies have been made of the enhanced transport during this phase and especially at high toroidal and poloidal betas. The saturation and the collapse of $\beta_{\text {tor }}$ or $\beta_{\text {pol }}$ can be caused by different physical mechanisms involving the plasma core and the edge of the plasma, but they mainly affect the confinement region. In this paper we will concern ourselves with losses originating at the plasma edge and then propagating into the confinement region.

Closely associated with the enhanced transport events described in this paper are ELMs, and especially grassy ELMs. The nain differences between the ELMs and the MHD events described in this paper are that the latter originate several $\mathrm{cm}$ inside the edge, while the ELMs, in ASDEX, DIII-D and other experiments originate near the separatrix. The other difference is that the PBX-1 1 Enhanced Transport Period (ETP) event propagates into the confinement

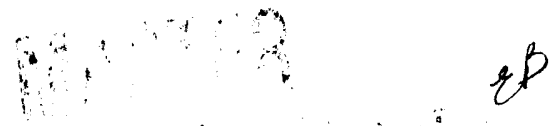


region more slowly. The different edge behavior relative to ASDEX and DIII-D is possibly due to the effect of the stabilizing plates near the plasma edge $(\Delta r / a=0.2)$ in PBX-M. The first descriptions of ELMs can be found in the earliest reports on the H-mode in ASDEX, PDX and DIII-D experiments $[1,2,3,4]$. Since then many papers described various aspects of ELMs.

The MHD events described in this paper that cause a transient enhancement in transport have been observed exclusively in $\mathrm{H}$-mode discharges during the $\beta$-rise, $\beta$-saturation or $\beta$ collapse $[5,6]$. For these plasmas, the plasma current was varied between 200 and $350 \mathrm{kA}$ and neutral beam injection between 2 and $5 \mathrm{MW}$. The toroidal field was approximately $1.3 \mathrm{~T}$, average densities were above $3 \times 10^{13} \mathrm{~cm}^{-3}$, electron and ion temperatures above 1 and $2 \mathrm{keV}$ respectively, elongation between 1.5 and 1.9 , indentation was $15 \%-18 \%$, and triangularity was 0.3 . The toroidal beta varied between 0.8 to $3.5 \%$. The poloidal beta was rather high and in the range of 0.8 to 2.5 .

The principal diagnostics used to obtain data on the transient enhancement of the transport were the soft $x$-ray diode array and the poloidal and toroidal magnetic probe arrays. The linesof-sight of the soft $x$-ray diode array superimposed on the flux surfaces are shown in Fig. 1. The distance between the midplane and the intersection of the line-of-sight and a vertical axis at $R_{0}=165 \mathrm{~cm}$ defines the radial profile dimension $\mathrm{z}$ used in the paper.

Section 2 is devoted to the description of this MHD phenomenon and Sec. 3 describes the difference in fluctuations during the periods of enhanced transport as relative to the quiet periods. In Sec. 4, the turbulent activity at the edge of the plasma, caused by these MHD events, is described. Section 5 closes this paper with a discussion of these transient enhanced transport events.

\section{Description of Periods of Enhanced Energy Loss}

Approaching a Troyon parameter of 4 , one can first observe a reduction of the rate of increase of $\beta$, and then a $\beta$-saturation. Sawteeth are observed during the period in which the rate of $\beta$ increase decreases, but the $\beta$-saturation is better correlated with the edge perturbations, which in the $\mathrm{H}$-alpha edge radiation look like the grassy ELM's. More discussion on these ELM-like perturbations will be given later. As the $\beta$-saturation sets in, more violent edge perturbations penetrate with increased depth into the confinement region. Occasionally one can observe a correlated decrease in $\beta$, but this drop can be spread over a shorter or longer time period. One such case is shown in Fig. 2, where the time evolution of $\beta$, together with the soft $x$-ray diode signals at the center $(z=0 \mathrm{~cm})$, in the confinement region $(z=23 \mathrm{~cm})$, and at the edge $(z=49$ $\mathrm{cm}$ ), and the beam power are shown. Note that the gradual drop in $\beta$ around $480 \mathrm{~ms}$, correlated with a drop of over $10 \%$ of the total energy, follows closely the drop in the signal of the SX diode at $\mathrm{z}=23 \mathrm{~cm}$, localized in the vicinity of the center or the confinement region. Neither the central nor the edge diodes show this drop. This period of enhanced transport (ETP), from 460 to $480 \mathrm{~ms}$, is followed in time by a period of normal transport (Normal 
Transport Period or NTP). Such strong and violent events are rather rare; more often one observes weaker ETP events of shorter duration (few ris), that might only slow down the rate of $\beta$ increase or, more often, cause the $\beta$ saturation. The ETP's are correlated in time with an increased edge pirturbation, resembling "grassy" ELM activity. The question of whether or not these are the "grassy" ELM's observed in other devices will he discussed later. During the NTP periods this edge activity almost disappears.

Of particular interest is an cstimate of the losses during the ETP. One can estimate the change in the confinement time due to the ETP by comparing the rate of rise or fall of $\beta$ during the NTP or ETP. The instantaneous energy confinement time can be written $\tau_{\mathrm{E}}=\beta /\left[\left(\beta \mathrm{P}_{\mathrm{T}}\right) / \mathrm{W}_{\mathrm{T}}\right.$ - $(d \beta / d t)]$, where $P_{T}$ is the total input power and $W_{T}$ the total plasma energy. The incremental energy confinement time during the NTP is estimated to be $61 \mathrm{~ms}$, and during the ETP it falls by factor of two to $31 \mathrm{~ms}$.

The evolution of the soft $x$-ray intensity loss during the ETP of Fig. 2 is shown in Fig. 3 for four time steps of $4 \mathrm{~ms}$ duration each. Here $\left(\mathrm{I}_{x}-\mathrm{I}_{\mathrm{xo}}\right) / \mathrm{I}_{\mathrm{xo}}$ is the normaiized intensity loss, where $\mathrm{I}_{\mathrm{xo}}$ is the soft $\mathrm{x}$-ray intensity at the start of the ETP and $\mathrm{I}_{\mathrm{x}}$ is the intensity at any other time during the ETP. The main loss in soft $x$-ray intensity occurs in the confinement region between $\mathrm{z}=15$ and 30 to $40 \mathrm{~cm}$. The core of the plasma, roughly the region with $\mathrm{q}<1$, and the edge region are not affected by the ETP. The evolution of the ETP in time seems to indicate that the ETP is initially localized in a smaller region, and that in time it propagates mainly outward. Integrating the soft $\mathrm{x}$-ray intensity loss over minor radius and assuming that the soft $\mathrm{x}$-ray emissivity is roughly proportional to the square of the plasma pressure (electron pressure) one finds the total loss of plasma energy during the ETP of Figs. 2 and 3 to be about 20\% of the initial plasma energy. This is in good agreement with magnetic measurements which show a loss of $20 \%$.

The ETP of Figs. 2 and 3 is followed by an NTP of $20 \mathrm{~ms}$ duration. During the NTP a large enhancement (between 20 to $30 \%$ ) in the soft $\mathrm{x}$-ray intensity occurs precisely in the same region where the losses during the ETP were the largest, indicating the replenishment of the lost energy in the confinement region.

\section{Fluctuations during ETP and NTP}

A large change in the heat and/or particle transport in the confinement region (roughly outside $\mathrm{q}$ $=1$ surface and inside the regicn dominaied by edge effects) is seen during the onset of the ETP. To help understand this sudden onset of poor confinement, extensive studies were made of both the soft $x$-ray and edge magnetic fluctuations during both the ETP and NTP periods, and highlights of these studies will be described below.

The fluctuation measurements in the core region show that there is no enhancement of fluctuations in the region for roughly $a<1$. However, both the confinement and the cdge 
regions show a large increase in fluctuations during the ETP period. An example of such a fluctuation enhancement during an ETP is shown in Fig. 4, where two spectral power profiles in the frequency band between 30 and $34 \mathrm{kHz}$ are displayed for the ETP and NTP periods, respectively. Similar profiles are obtained for the lower and the higher frequencies, except that the enhancement factor in the confinement region is higher for the lower frequencies (larger than 5 at $5 \mathrm{kHz}$ ), and lower for the higher frequencies (enhancement of only $20 \%$ at $100 \mathrm{kHz}$ ). The studies also show that the very low fluctuation frequencies are associated mainly with the edge region of the plasma. The very last points in the profiles of Fig. $4(\mathrm{z} \geq 60 \mathrm{~cm})$ show that in the separatrix region (outside), there is no enhancement in the fluctuations during the ETP. In most cases, the photon noise prevents fluctuation measurements above $100 \mathrm{kHz}$. The relative fluctuation levels vary, depending on frequency, from $0.1 \%$ at $30 \mathrm{kHz}$ in the center to $20 \%$ at 5 $\mathrm{kHz}$ at the edge.

A similar picture of edge magnetic fluctuations and their spectra is observed when the fluctuations in the magnetic probes separated poloidally near the plasma edge are investigated. There is a large change in the signature of the magnetic probe signals between the small and large major radius sides. The inside probe shows an ETP enhancement over the whole frequency range of at least a factor of three. The outer probe shows a stronger ETP enhancement for lower frequencies up to $20 \mathrm{kHz}$ (a factor of two), but a very weak enhancement for higher frequencies. The comparison of spectra on the inside and outside probes during either the ETP or NTP shows that the fluctuation levels at the outer side of the plasma is higher, especially at higher frequencies $(>10 \mathrm{kHz})$, indicating a possible ballooning character for these quasi-turbulent perturbations.

\section{MHD and Turbulent Activity in Edge Region}

The PBX-M data show that the edge region during a high- $\beta$ discharge is very turbulent. At the very early stage of the $\beta$-saturation, weak, low frequency, solitary edge perturbations, reminiscent of grassy ELMs, with a low repetition rate of less than $1 \mathrm{kHz}$, are observed (Fig. 5). The structure of these perturbations, measured by the horizontal soft x-ray array, resembles an $\mathrm{m}=$ even mode. Initially, no precursor to this perturbation is observed, but later these solitary perturbations show a precursor of typically 20 to $50 \mathrm{kHz}$. This earlier perturbation seems to originate around $\mathrm{z}=43 \mathrm{~cm}$; the perturbation seems to propagate inward in about $600 \mu \mathrm{s}$ and is up/down symmetric. In the edge region from $(\mathrm{z}=56$ to $\mathrm{z}=32 \mathrm{~cm})$ the amplitude of this periurbation can increase inward by a factor of 30 , but between $\mathrm{z}=20$ and $19 \mathrm{~cm}$ the perturbation does not increase much. Each of these $m=e v e n$ events appear to cause a loss in energy of less than $1 \%$. They are similar to grassy ELMs observed on DIII-D and ASDEX, but they are most probably a different edge phenomenon because of their apparent radial propagation inward. They also originate farther away from the separatrix and inside the plasma, whereas the grassy ELMs in ASDEX and DIII-D seem to originate just inside the 
separatrix. As the $\beta$-value increases, this perturbation becomes gradually stronger and more complex and chaotic.

Later in the discharge, especially during the $\beta$-saturation and collapse and during the ETP periods, a more violent type of edge turbulence is observed (Fig. 6). This violent type of edge and confinement region turbulence evolves slowly from the more benign, solitary $m=e v e n$ events. This evolution from benign to turbulent perturbations, which may indicate an evolution of the controlling physics as well, is also observed in the magnetics. From Fig. 6, one can distinguish several features in the diode signals. The most obvious is the low frequency perturbation and crashes. These soft $\mathbf{x}$-ray low frequency perturbations and crashes are often initiated by a growing 30 to $50 \mathrm{kHz}$ precursor. The precursor is localized poloidally (observed either in the "up" or "down" diodes, but not both) and radially (between $\mathrm{z}=40$ and $55 \mathrm{~cm}$ ). The precursor mode often ends in an inverted-sawtooth-like crash seen in the edge diodes. The inverted sawtooth-like crash is observed almost simultaneously at the edge and in some of the confinement region diodes. This is unlike the $600 \mu$ s propagation time of the solitary $\mathrm{m}=\mathrm{even}$ events. These events create a heat pulse which is observed in both the edge diodes and the $\mathrm{H}$ alpha emission. They do not exhibit an inversion radius. These violent perturbations and accompanying $\mathrm{H}$-alpha spikes also resemble irregular grassy ELM's. The precursor crash is accompanied by a high-frequency burst in the Mirnov coils. The high-frequency burst is on the order of $200 \mathrm{kHz}$, with a clear coherent oscillatory structure. The duration of this high frequency burst in the Mirnov coil is short: between 50 to $100 \mu \mathrm{s}$. It is important to stress that the ETP is just a collection of violent $m=e v e n$ events with a high degree of turbulence, showing up in the edge and in part of the confinement region.

As was mentioned ETPs can cause either $\beta$-saturation or $\beta$-r ollapse. Also observed to cause a $\beta$-collapse is a continuous $n=1$ mode, interspersed with giant ELMs. In fact, the latter activity is observed in most of the high- $\beta_{\text {pol }}, \beta$-collapse cases. We note, however, that the ETP and the $n=1 / E L M$ activity are mutually exclusive.

The ETPs can occur also in the medium- $\beta \mathrm{H}$-mode with a delay of a few ms after the sawtooth. This ETP is triggered by the sawtooth, lasts for about $10 \mathrm{~ms}$, and seems to carry the energy, accumulated after the sawtooth crash outside the $q=1$ surface, to the edge of the plasma. After this excess energy has been transported to the edge, a quiet NTP period follows, lasting 5 to $10 \mathrm{~ms}$ for the rest of the sawtooth period. With the new sawtooth, the ETP/NTP sequence begins anew. This kind of sawtooth/ETP/NTP sequenced activity causes a repeated deterioration of the profile with a gradual loss in total plasma energy and, therefore, a $\beta$ collapse.

Often correlated with ETPs are a delayed saturation or even a decrease in the neutron iate, indicating that the ETPs also affect the thermal and fast ions in the core of the plasma. This is probably due to an increased diffusion due to the modification of gradients in the confinement region. 


\section{Discussion}

We have established the correlation between the ETPs, the turbulent $m=e v e n$ events, the enhanced low-frequency turbulent fluctuations, and the degradation of the energy confinement. The low-frequency turbulence is composed of turbulent $m=e v e n$ events, and is possibly the trigger for the confinement degradation. On the other hand, the observations show that the strongest relative (normalized) turbulence does not reside in the confinement region, where the losses are the highest, but in the edge region of the plasma. This would indicate that this observed low frequency turbulence is not the cause for the ETP, but most probably its effect, seen most strongly at the edge of the plasma. We can now propose a possible scenario for ETP-induced enhanced losses. The ETPs, causing a strong profile erosion in the confinement region, carry the energy to the region a few $\mathrm{cm}$ from the edge of the plasma, where this surge of energy triggers a violent $m=$ even event. The turbulent $m=$ even event carrics the energy to the separatrix region. On the other hand, the turbulent $m=e v e n$ event, also propagating inward, causes a further profile erosion in the confinement region, and the cycle begins anew.

Obviously the key for understanding the ETP is to resolve the questions of what physical mechanism triggers the edge $m=e v e n$ event and how can this edge phenomenon propagate deep into the confinement region, causing a large soft $\mathrm{X}$-ray profile erosion. It has been shown for similar PBX-M discharges that the ballooning modes are stable in the edge region, but that the external kink modes are unstable $[5,6,7]$. Therefore, the trigger for the $m=e v e n$ could even be an external kink mode. The question of enhanced erosion in the confinement region, triggered by the $m=e v e n$ event, is not resolved. This process is not diffusive and it is possible that the $m=e v e n$ event at the edge of the plasma causes some instability to propagate inward. It is obvious that the picture of a turbulent $m=e v e n$ event is not a simple one and that during the ETP, we are encountering more than one physical process. However, this problem is not unique to the turbulent $m=e^{-e n}$ events and the ETPs; the same process occurs with giant ELMs, which in PBX-M also originate a few $\mathrm{cm}$ inside the separatrix and then propagate inward into the confinement region on an even shorter time scale.

\section{Acknowledgments:}

This work was supported by the United States Department of Energy Contract No. DE-AC0276-CHO3073.

* ORNL, Oak Ridge, TN 37381, USA 


\section{References:}

[1] Wagner, F., Becker, G., Behringer, K., et al., 1983 Plasma Physics and Controlled Nuclear Fusion Research (Proc. 9th Int. Conf. Baltimore, 1982), Vol. 1, IAEA, Vienna (1983) 43-55

[2] Kaye, S., Bell, M., Bol, K., et al., 1984 J. Nucl. Mater. 121, 115-125

[3] Burrell, K., Ejima, S., Schissel, D., et al., 1987 Phys. Rev. Lett. 59, 1432-1435

[4] ASDEX Team, $1989 \mathrm{Nucl}$. Fusion 29, 1959-2040

[5] Sauthoff, S., Asakura, N., Bell, R., et al., 1991 Proceedings of the 13th Intern. Conf. on Plasma Phys. and Contr. Nucl. Fus. Research (Washington, DC, October 1990), (IAEA, Vierına, Austria) Vol. I, 709-722

[6] Bell, R. E. , Asakura, N., Bernabei, S., et al., 1990 Phys. Fluids B 2, 1271-1279

[7] Kaye, S. M., Manickam, J., Asakura, N., et al., $1990 \mathrm{Nucl}$. Fusion 30, 2621-2627 


\section{Figure Captions:}

Fig. 1. Equilibrium magnetic surfaces for a high $\beta_{\text {pol }}$ discharge.The lines-of-sight of the soft $\mathrm{x}$-ray diode array with the definition of the diode position, $\mathrm{z}$, is also shown.

Fig. 2. Time evolution of $\beta_{\text {tor }}$, average line density, $\left\langle n_{\mathrm{e}}\right\rangle$, soft $x$-ray diode signal, $I_{x}$, edge $\mathrm{H}$-alpha radiation, $\mathrm{I}_{\mathrm{H}}$, and beam power, $\mathrm{P}_{\mathrm{b}}$. A large ETP is observed between 465 and $490 \mathrm{~ms}$.

Fig. 3. Consecutive profiles of normalized intensity loss, $\left(\mathrm{I}_{\mathrm{x}}-\mathrm{I}_{\mathrm{xo}}\right) / \mathrm{I}_{\mathrm{xo}}$, during ETP of Fig. 1. Profiles are separated by $4 \mathrm{~ms}$. The largest normalized losses are observed in the region between $\mathrm{z}=20$ and $40 \mathrm{~cm}$.

Fig. 4. Profiles of fluctuation power in the frequency band between 30 to $34 \mathrm{kHz}$. Curve $a$ represents the fluctuations during an ETP, curve $b$ during the following NTP, and $c$ is the equivalen photon noise.

Fig. 5. Two solitary $m=e v e n$ events observed with soft $x$-ray diode array of Fig. 1 . The $\mathrm{m}=\mathrm{even}$ events originate at the edge of the plasma and propagate inward in about $0.6 \mathrm{~ms}$.

Fig. 6. Signals of a Mirnov probe, $I_{M}$, central soft $x$-ray diode and edge diodes, $I_{x}$, showing a turbulent behavior in the edge diodes during an ETP. Turbulence is caused by a series of violent $m=e v e n$ events. 


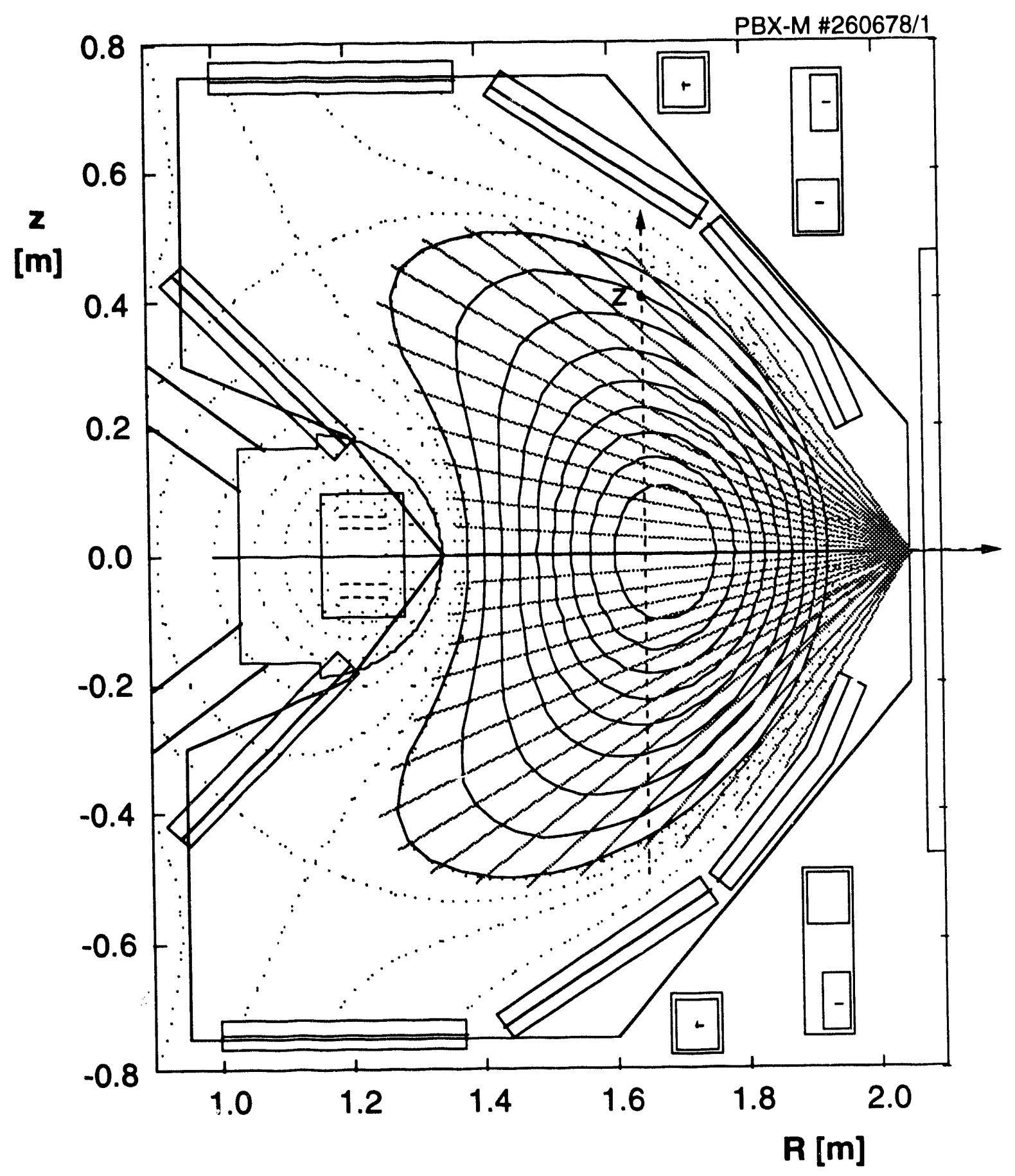

Fig. 1 


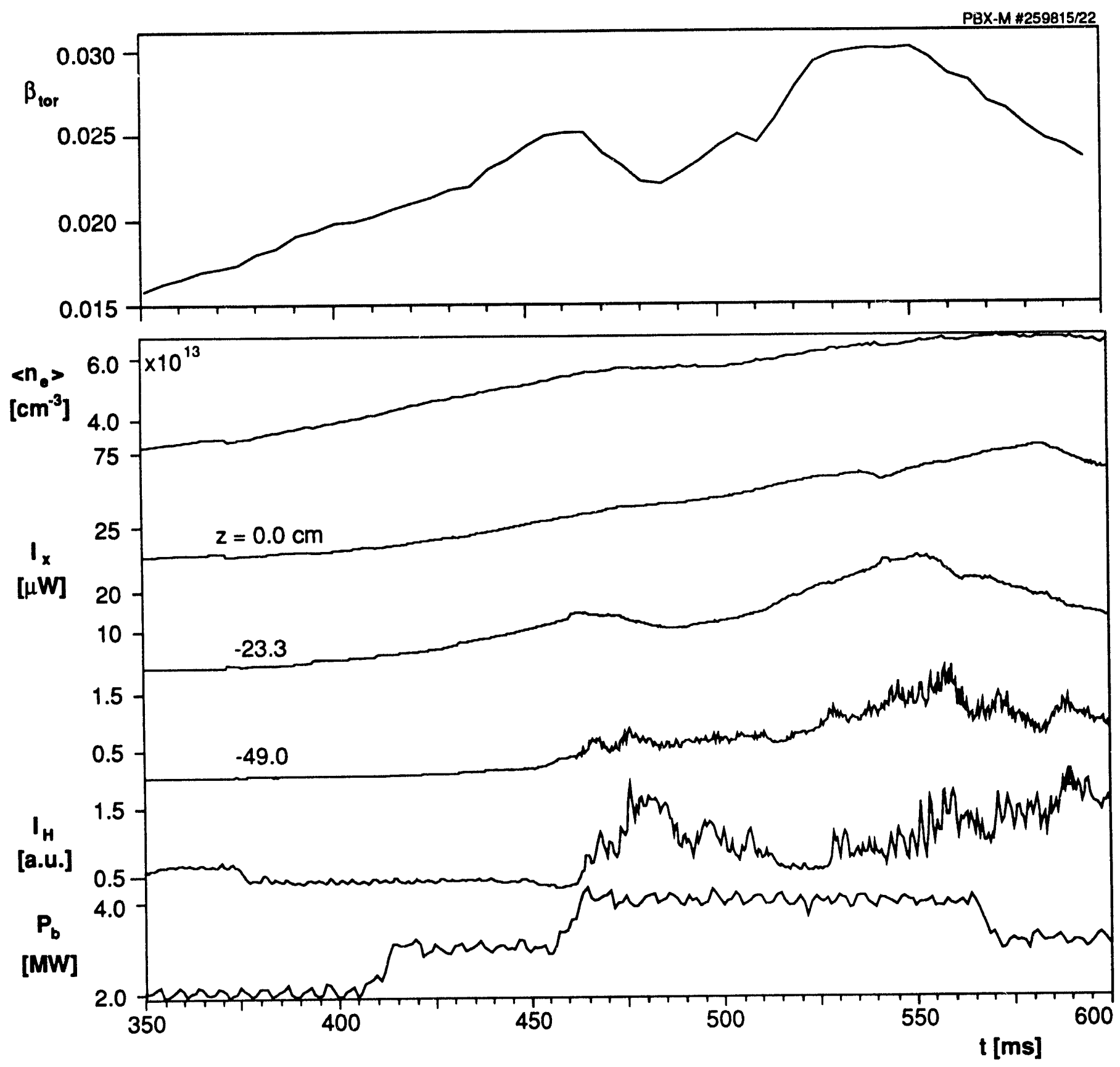

Fig. 2 


$$
F
$$




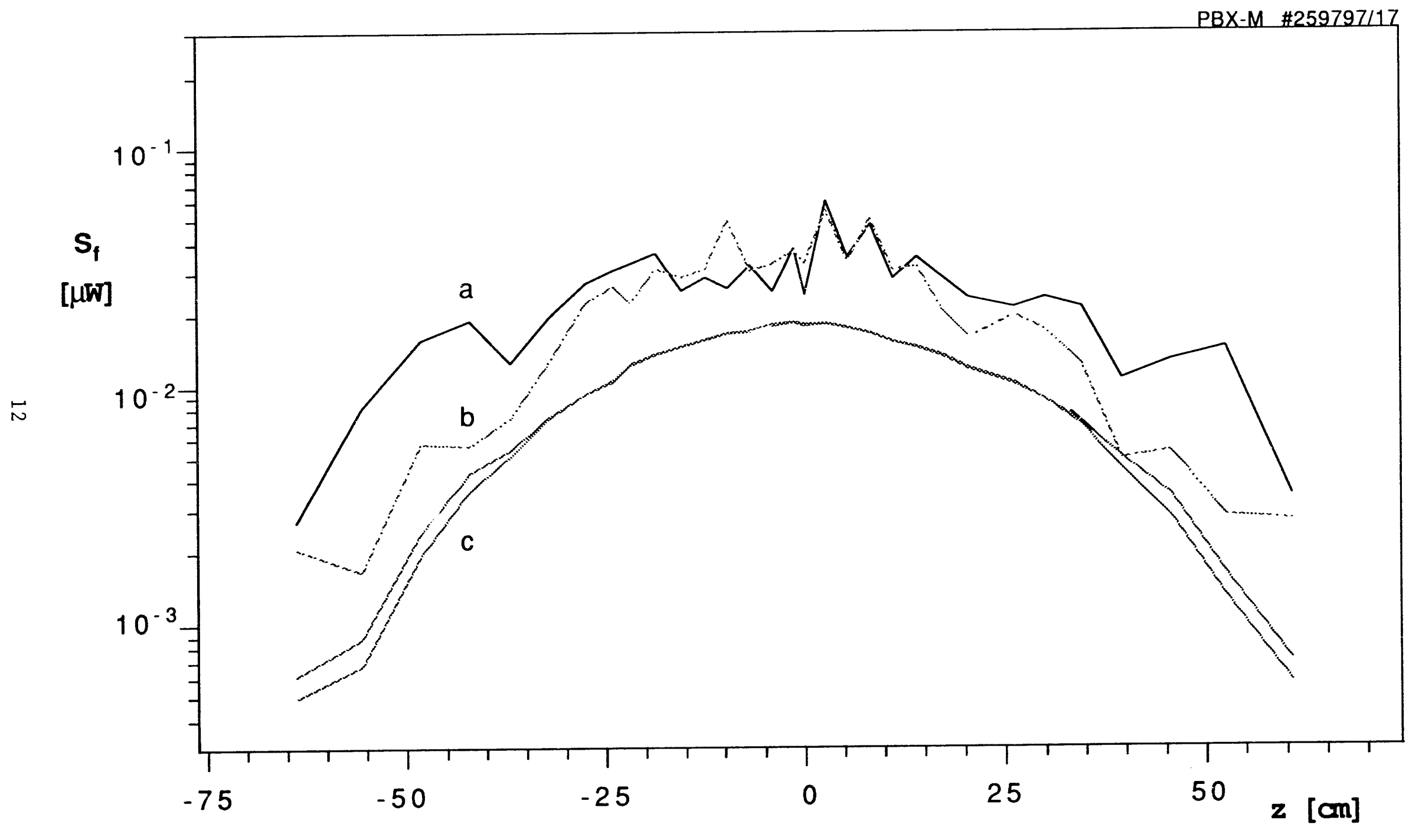

Fig. 4 
PBX-M \#259787/6

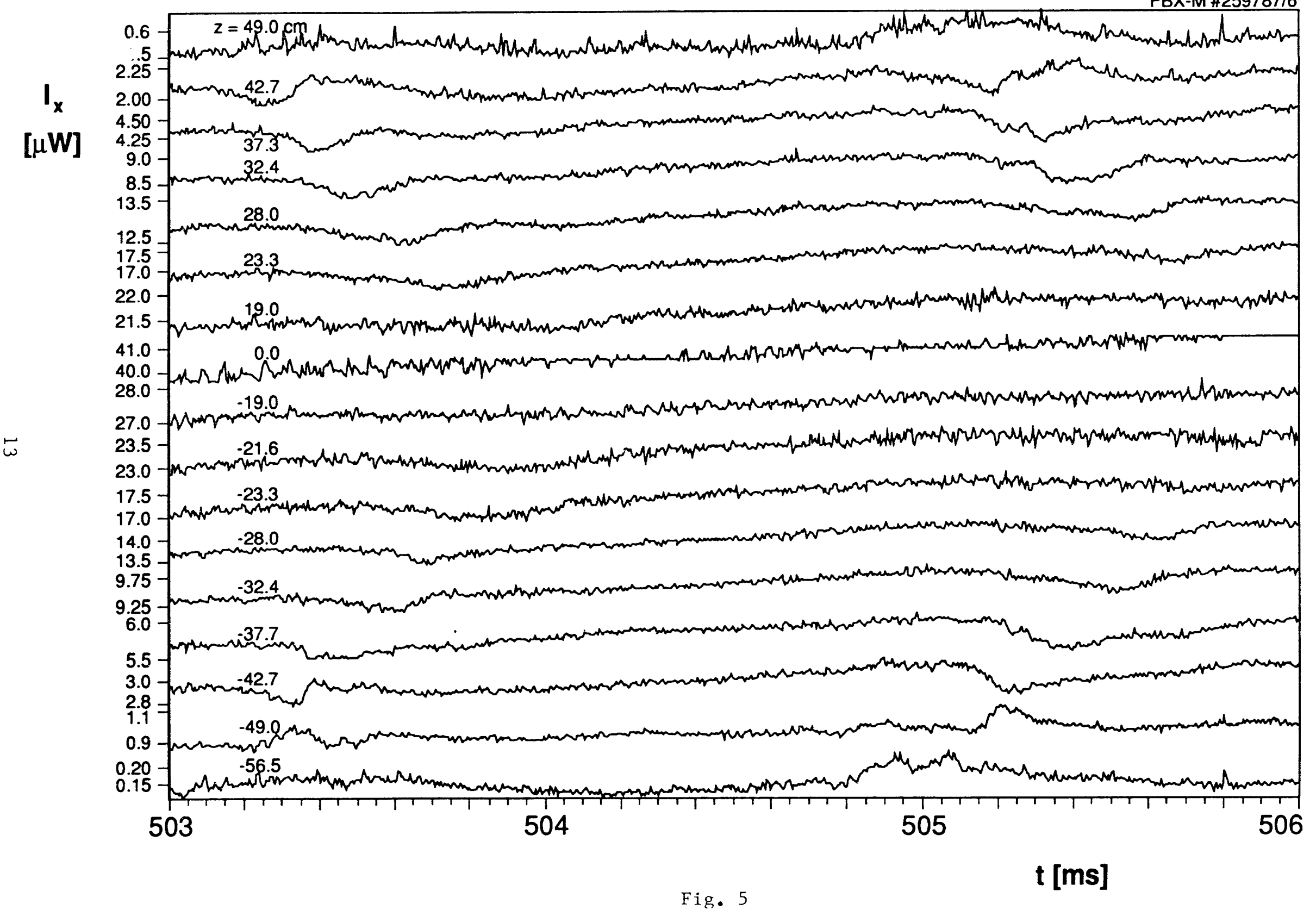

Fig. 5 
PBX-M \#259795/2

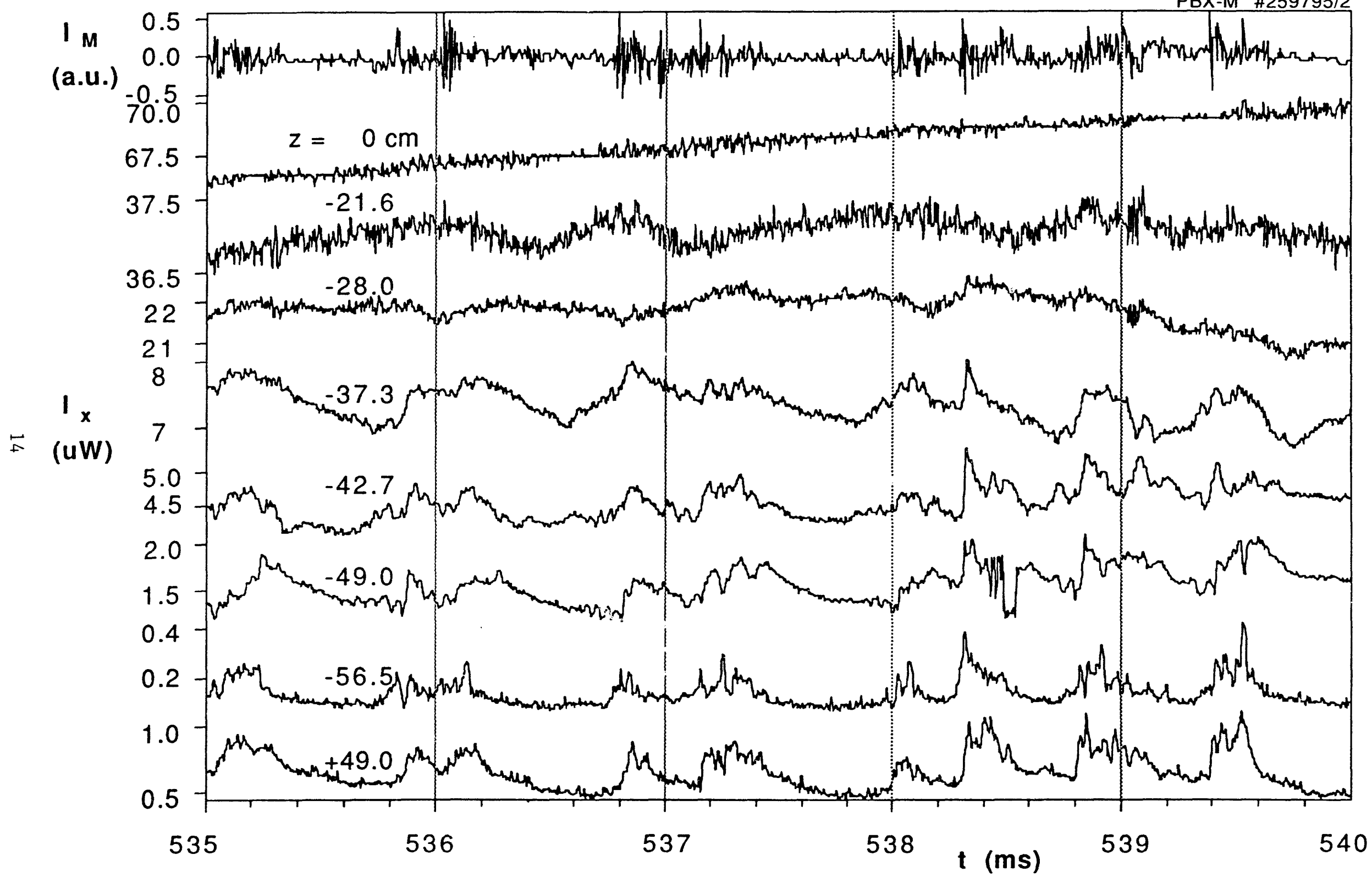




\section{EXTERNAL DISTRIBUTION IN ADDITION TO UC-420}

Dr. F. Paoloni, Univ. of Wollongong, AUSTRALIA

Prof. M.H. Brennan, Univ, of Sydney, AUSTRALIA

Plasma Research Lab., Australian Nat. Univ., AUSTRALIA

Prof. I.R. Jones, Flinders Univ, AUSTRALIA

Prot. F. Cap, Inst. for Theoretical Physics, AUSTRIA

Prot. M. Heindler, Instivit ïr Theoretische Physik, AUSTRIA

Prof. M. Goossens, Astronomisch Instituut, BELGIUM

Ecole Royale Militaire, Lab. de Phy. Plasmas, BEL GIUM

Commission-European, DG. XII-Fusion Prog., BELGIUM

Prof. R. Bouciqué, Rijksuniversiteit Gent, BELGIUM

Dr. P.H. Sakanaka, Instituto Fisica, BRAZIL

Prof. Dr. I.C. Nascimento, Instituto I ica, Sao Paulo, BRAZIL Instituto Nacional De Pesquisas Espaciais-INPE, BRAZIL. Documents Office, Atomic Energy of Canada Ltd., CANADA Ms. M. Morin, CCFMTokamak de Varennes, CANADA Dr. M.P. Bachynski, MPB Technologies, Inc., CANADA Dr. H.M. Skarsgard, Univ. of Siskatchewan, CANADA Prof. J. Teichmann, Univ. of Montreal, CANADA Prof. S.R. Sreenivasan, Univ. of Calgary, CANADA

Prof. T.W. Johnston, INRS-Energie, CANADA

Dr. R. Bolton, Centre canadien de fusion magnétique, CANADA

Dr. C.R. James., Univ. of Alberta, CANADA

Dr. P. Lukác, Komenskèho Universzita, CZECHO-SLOVAKIA

The Librarian, Culham Laboratory, ENGLAND

Library, R61, Ruthertord Appieton Laboratory, ENGLAND

Mrs. S.A. Hutchinson, JET Library, ENGLAND

Dr. S.C. Shama, Univ of South Pacific, FIJI ISLANDS

P. Mähönen, Univ. of Helsinki, FINLAND

Prof. MN. Bussac, Ecole Polytechnique., FRANCE

C. Mouttet, Lab. de Physique des Milieux lonisés, FRANCE

J. Radet, CEN/CADARACHE - Bat 506, FRANCE

Prot. E. Economou, Univ. of Crete, GREECE

Ms. C. Rinni, Univ. of loannina, GREECE

Preprint Library, Hungarian Academy of Sci., HUNGARY

Dr. B. DasGupta, Saha Inst. of Nuclear Physics, INDIA

Dr. P. Kaw, Inst. for Plasma f jearch, INDIA

Dr. P. Rosenau, Israel Inst. of Technology, ISRAEL

Librarian, Intemationai Center for Theo Physics, ITALY

Miss C. De Palo, Associazione EURATOM-ENEA, ITALY

Dr. G. Grosso, Istruto di Fisica del Plasma, ITALY

Prof. G. Rostangni, Istituto Cas Ionizzati Del Cnr, ITALY
Dr. H. Yamato, Toshiba Res \& Devel Center, JAPAN

Prof. I. Kawakami, Hiroshima Univ., JAPAN

Prof. K. Nishikawa, Hiroshima Univ., JAPAN

Librarian, Naka Fusion Research Establishment, JAERI, JAPAN

Director, Japan Alomic Energy Research Inst., JAPAN

Prof. S. Itoh, Kyushu Univ., JAPAN

Research Info. Ctr., National Instit. for Fusion Science, JAPAN

Prof. S. Tanaka, Kyoto Univ., JAPAN

Library, Kyoto Univ., JAPAN

Prof. N. Inove, Univ. of Tokyo, JAPAN

Secretary, Plasma Section, Electrotechnical Lab., JAPAN

S. Mori, Technical Advisor, JAERI, JAPAN

Dr O. Mitarai, Kumamoto Inst. of Technology, JAPAN

Dr. G.S. Lee, Korea Basic Sci. Ctr., KOREA

J. Hyeon-Sook, Korea Atomic Energy Research Inst., KOREA

D.I. Choi, The Korea Adv. Inst. of Sci. \& Tech., KOREA

Prof BS Liley, Univ of Waikato, NEW ZEALAND

Inst of Physics, Chinese Acad Sci PEOPLE'S REP. OF CHINA

Library, Inst. of Plasma Physics, PEOPLE'S REP. OF CHINA

Tsinghua Univ. Library, PEOPLE'S REPUBLIC OF CHINA

Z L.S.W. Inst Physics, PEOPLE'S REPUBLIC OF CHINA

Prot JA.C Cabral, Instituto Superior Tecnico, PORTUGAL

Prot. M.A. Hellberg. Univ. of Natal, S. AFRICA

Prof D.E. Kim, Pohang Inst. of Sci. \& Tech., SO. KOREA

Prot C.I.E.M.A.T. Fusion Division Library, SPAIN

Dr. L. Stenflo, Univ. of UMEA, SWEDEN

Library, Royal Inst of Technology, SWEDEN

Prof H. Wilhelmson, Cr almers Univ. of Tech., SWEDEN

Centre Phys Des Plasmas, Ecole Polytech. SWITZERLAND

Bibliotheek, Inst. Voor Plasma-Fysica, THE NETHERLANDS

Asst. Prot Dr. S Cakir, Middle East Tech. Univ., TURKEY

Dr. VA Giukhikh, Sci. Res. Inst. Electrophys.I Apparatus, USSR

Dr. D.D Ryutov, Siberian Branch of Academy of Sci., USSR

Dr. G.A. Eliseev, I.V. Kurchatov Inst., USSR

Libranan, The Ukr.SSR Academy of Sciences, USSR

Dr. L.M. Kovrizhnykh, Inst of General Physics, USSR

Kerntorschungsanlage GmbH, Zentralbibliothek, W. GERMANY

Bibliothek, Inst Für Plasmatorschung, W. GERMANY

Prof K. Schindier, Ruhr-Universitát Bochum, W. GERMANY

Dr. F. Wagner, (ASDEX), Max-Planck-Institut, W. GERMANY

Librarian, Max-Planck-Institut, W. GERMANY 

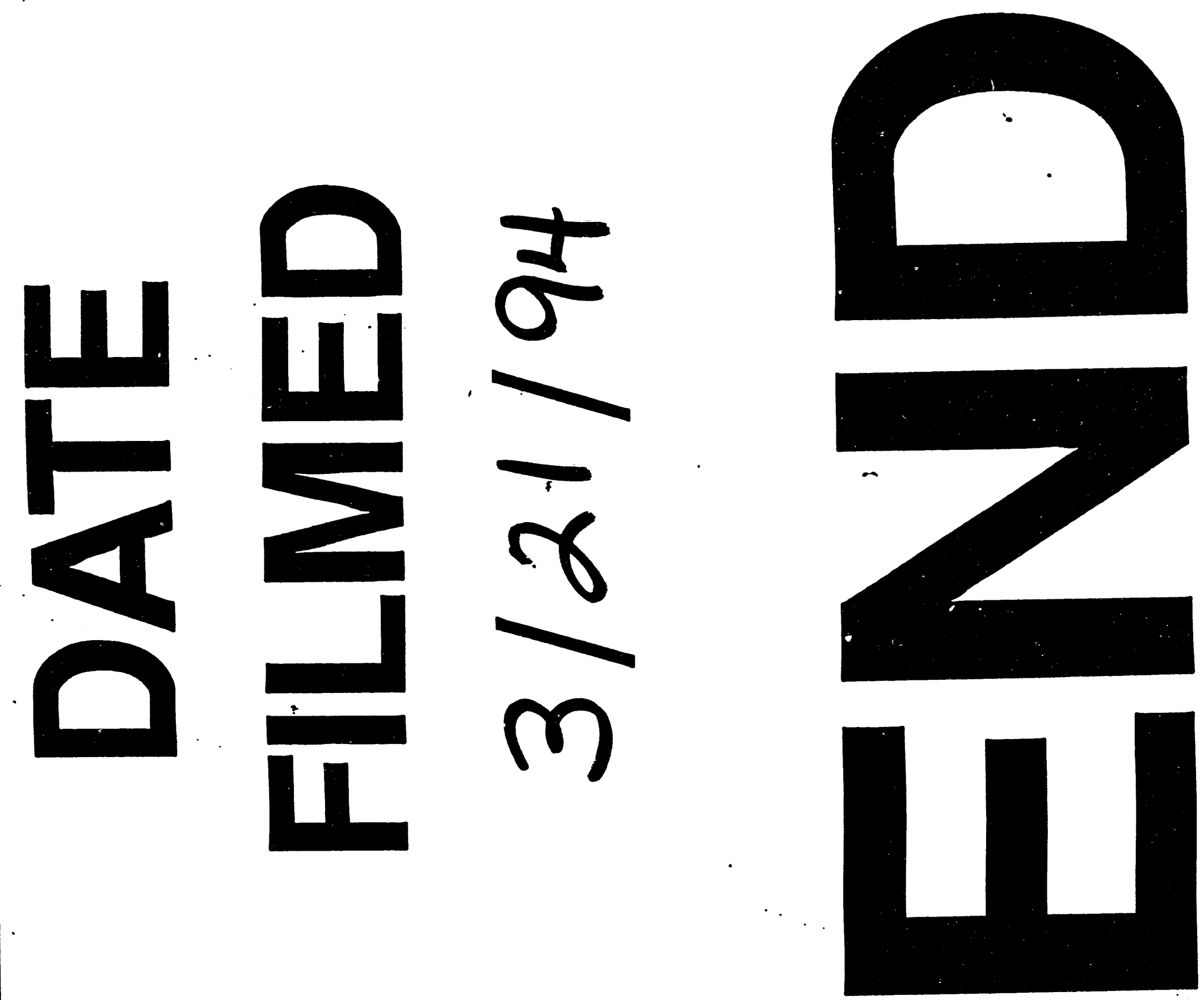


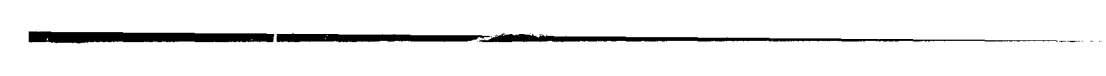

